\title{
Matrine-induced apoptosis in Hep3B cells via the inhibition of MDM2
}

\author{
NING ZHOU, JIEQUN LI, TING LI, GUANGSHUN CHEN, ZHONGQIANG ZHANG and ZHONGZHOU SI \\ Department of Organ Transplantation and General Surgery, \\ The Second Xiangya Hospital of Central South University, Changsha, Hunan 410011, P.R. China
}

Received August 7, 2015; Accepted August 22, 2016

DOI: $10.3892 / \mathrm{mmr} .2016 .5999$

\begin{abstract}
Matrine, an alkaloid component derived from the Sophora root, can inhibit cancer cell proliferation and induce autophagy via p53 associated pathways. However, numerous tumor cells lack functional p53 and little is known about the effect of matrine on the p53-deficient/mutant cancer cells. The present study aimed to assess anticancer effects of matrine in p53-deficient human Hep3B hepatoma cells. The present results demonstrated that matrine caused Hep3B cell apoptosis by suppressing gene expression of minute double-mutant (MDM)2. Notably, it was revealed that matrine inhibited MDM2 at the transcriptional level in a time- and dose-dependent manner. This MDM2 inhibition resulted in induction of the p53 family member, p73; however, the functions of p73 were not induced since matrine-induced p73 failed to activate its target genes, p21 and p53 upregulated modulator of apoptosis. The matrine-induced downregulation of MDM2 led to an inhibition of inhibitor of apoptosis protein 3, which might serve a critical role in matrine-induced apoptosis in MDM2-overexpressing Hep3B cells. Finally, combination therapy of matrine with $100 \mu \mathrm{M}$ epotoside successfully killed more Hep3B cells, suggesting that matrine can sensitize p53-deficient Hep3B cells to epotoside-induced apoptosis.
\end{abstract}

Correspondence to: Dr Zhongzhou Si, Department of Organ Transplantation and General Surgery, The Second Xiangya Hospital of Central South University, 87 Xiangya Road, Changsha, Hunan 410011, P.R. China

E-mail: zhongzhousihn2015@163.com

Abbreviations: MDM2, mouse double-minute 2; DMSO, dimethylsulfoxide; CHX, cycloheximide; MPTP, mitochondrial permeability transition pore; PUMA, p53 upregulated modulator of apoptosis; IAPs, inhibitors of apoptosis protien; DDR, DNA damage response; DMEM, Dulbecco's modified Eagle's medium; MTT, 3-(4,5-dimethyl-2-thiazolyl)-2,5-diphenyl-2-H-tetrazolium bromide; PI3K, phosphatidylinositol 3-kinase

Key words: matrine, p73, apoptosis, MDM2, Hep3B

\section{Introduction}

Matrine is a component of the traditional Chinese medical herb Sophora flavescens ait. It performs a variety of medical effects as a $\kappa$-opioid receptor and $\mu$-receptor agonist (1). Since Matrine has a wide range of clinical effects, including anti-inflammatory, antiviral, immunoinhibitory, antifibrotic and antidiarrhea effects $(2,3)$, it has been widely used in treatment of viral hepatitis, hepatic fibrosis, cardiac arrhythmia and skin diseases, including atopic dermatitis and eczema in China (4-7). Therefore, matrine can serve as a potential anticancer drug to treat various types of human cancer. A previous study reported that matrine can suppress the proliferation of hepatoma G2 (HepG2) cells, possibly by inducing apoptosis through the activation of B-cell lymphoma-2-activated X protein (8). However, its antitumor mechanism in p53 deficient hepatoma Hep3B cells remains to be elucdated.

In response to various cellular stresses, the tumor suppressor gene, p53, acts as an important safeguard mechanism by preventing cells from undergoing uncontrolled proliferation in response to DNA damage $(9,10)$. The downstream DNA damage response (DDR) involves a series of events that lead to either cell-cycle arrest induced by p21 or apoptosis induced by $\mathrm{p} 53$ upregulated modulator of apoptosis (PUMA) (11). Mouse double-minuted (MDM)2, a target gene of p53 that can form a negative feedback loop with p53, it is also considered as an antiapoptotic factor that can inhibit apoptosis of tumor cells (12). MDM2 has attracted great attention following its identification as a negative modulator of p53. MDM2 can bind to p53 through its $\mathrm{N}$-terminus to repress $\mathrm{p} 53$ anticancer functions, while its $\mathrm{C}$-terminus serves as an E3 ubiquitin ligase to mediate p53 degradation, which maintains p53 at a low protein level during normal homeostasis without stress signals (12-14). In addition to interacting with and modulating p53, MDM2 may compete with effectors that are capable of binding with p73 (15-17). With the exception of interacting with and regulating p53 family members, growing evidence suggests that MDM2 has numerous p53-independent functions. For example, MDM2 was shown to bind to and ubiquitinate $\mathrm{Rb}$, resulting in $\mathrm{Rb}$ degradation and release of E2F1, which promotes cell cycle progression $(18,19)$. Since MDM2 is able to bind RNA and shuttle between the nucleus and the cytoplasm, properties of most 
internal ribosome entry site (IRES) trans-acting factors (ITAFs)/ribonucleoproteins (RNPs), this suggests that the dephosphorylated cytoplasmic MDM2 may act as an ITAF/RNP to regulate translation through binding of its C-terminus to specific RNAs (20). Additionally, previous studies also demonstrated that MDM2 can physically interact with the IRES of the 5'-untranslated region of inhibitor of apoptosis protein (IAP)3, and in turn induce translation of the latter, which allows for development of resistance to anticancer treatment $(21,22)$.

As a negative modulator of $\mathrm{p} 53$, it may be suggested that MDM2 is an indirect oncogene, when overexpressed would be oncogenic by preventing the release of activated p53. This hypothesis is supported by numerous previous studies $(23,24)$. For example, in MDM2 overexpression mice, the incidence rate of tumor formation is significantly increased. In particular. MDM2 overexpression is even observed in cancer types that lack MDM2 gene amplification, including acute lymphoblast leukemia cells $(23,24)$. Regardless of any molecular mechanism involved, MDM2 overexpression is associated with the development of tumors and poor prognosis.

A previous study reported that matrine at concentrations of $0.25,0.5,1.0$ and $2.0 \mathrm{mg} / \mathrm{ml}$ inhibits the growth of HepG2 cells in a dose- and time-dependent manner (8). The present study used identical concentrations of matrine with minimal modification to investigate the influence of matrine on MDM2 expression and induction of Hep3B cell death. It was revealed that matrine markedly suppressed MDM2 transcription and caused significant apoptosis of MDM2-overexpressing Hep3B cells. In addition, the present study examined the expression of the p53 family member, p73, as well as its downstream effectors, p21 and PUMA. Investigating these effects may assist with elucidating the molecular mechanism by which matrine induces MDM2 downregulation and apoptosis of the p53-deficient Hep3B cells.

\section{Materials and methods}

Reagents. Matrine was supplied by Xi'an Tianyuan Biologics Plant (Xi'an, China), with a purity of $>99 \%$. Matrine was dissolved in sterile double distilled water at a stock concentration of $40 \mathrm{mg} / \mathrm{ml}$, was stored at $-20^{\circ} \mathrm{C}$ in the dark and was subsequently diluted in Dulbecco's modified Eagle's medium (DMEM) to obtain the desired concentration. Actinomycin D, benzo(a)pyrene and etoposide were purchased from Sigma-Aldrich (St. Louis, MO, USA). DMEM and fetal bovine serum (FBS) were products from Gibco (Thermo Fisher Scientific, Inc., Waltham, MA, USA). The protein isolation kit was obtained from KeyGen Biotech. Co., Ltd. (Nanjing, China). MDM2 CRISPR activation plasmid, and MDM2 (cat. no. BS1223), PUMA (cat. no. AB10418), p73 $\alpha$ (cat. no. 4662), p73 $\alpha$ (Try99) (cat. no. 4665S) and $\beta$-actin (cat. no. 4967) antibodies were all obtained from Santa Cruz Biotechnology, Inc. (Santa Cruz, CA, USA). IAP3 (2F1) antibody (cat. no. ab5746) was purchased from Abcam (Cambridge, MA, USA). An mRNA extraction kit and SYBR green I mix for quantitative polymerase chain reaction (qPCR) were supplied by Qiagen (Hilden, Germany) and Invitrogen (Thermo Fisher Scientific, Inc.), respectively. Activated caspase-9 (cat. no. BS7070), activated caspase-3 (cat. no. BS4301) and activated poly ADP-ribose polymerase (PARP; cat. no. BS7047) antibodies, as well as IRDye-conjugated secondary antibodies (cat. no. BA29880) were all purchased from Bioworld Technology, Inc. (St. Louis Park, MN, USA). The dilution ratio of all primary and secondary antibodies were 1:500 and 1:5,000, respectively. The annexin V-fluorescein isothiocyanate (FITC)/propidium iodide (PI) apoptosis detection kit was purchased from Multi-Sciences Biotechnology (Hangzhou, China).

Cell culture and treatment. Both Hep3B and L0-2 cells were obtained from the Cell Bank of Type Culture Collection of the Chinese Academy of Science (Shanghai, China). The two cell lines were grown in DMEM containing $10 \%$ (v/v) FBS and were cultured at $37^{\circ} \mathrm{C}$ in a humidified $5 \% \mathrm{CO}_{2}$ atmosphere.

Western blotting. Hep3B and L0-2 cells were collected and lyzed in a traditional radioimmunoprecipitation buffer (1 M Tris- $\mathrm{HCl}, 5 \mathrm{M} \mathrm{NaCl}, 1 \%$ Nonidet P-40, $1 \%$ sodium deoxycholate, $0.05 \%$ SDS and $1 \mathrm{mM}$ phenylmethylsulfonyl fluoride) for $15 \mathrm{~min}$. The proteins were denatured at $96^{\circ} \mathrm{C}$ for $5 \mathrm{~min}$ following mixing with $5 \mu \mathrm{l}$ SDS-loading buffer. The proteins were subsequently separated on $12 \%$ SDS-PAGE gels and were transferred onto polyvinylidene difluoride membranes (EMD Millipore, Billerica, MA, USA). The immunoblotting assay was performed as described previously (25). The protein band densities were measured using Quantity One software (Bio-Rad, Hercules, CA, USA). The data was expressed as the density normalized against that of $\beta$-actin.

Reverse transcription (RT)-qPCR. The total RNA was extracted from cells using the RNeasy Mini kit (cat. no. 75144; Qiagen), according to the manufacturer's protocol. cDNA synthesis was performed using $1 \mu \mathrm{g}$ total RNA sample mixed with dNTP, reverse transcriptase, random monomers, oligo-dT as primers, $10 \mathrm{X}$ reaction buffer and DNAse I. The samples were run in a PCR system (T100; Bio-Rad) at the following temperatures: $42^{\circ} \mathrm{C}$ for $55 \mathrm{~min}, 70^{\circ} \mathrm{C}$ for $10 \mathrm{~min}$ and $4^{\circ} \mathrm{C}$ until collected. The samples were stored at $4^{\circ} \mathrm{C}$. The amplification was performed using a 7900 Real-Time PCR system (Applied Biosystems; Thermo Fisher Scientific, Inc.), according to the manufacturer's protocol for the Quanti-Fast SYBR Green RT-PCR kit (Qiagen). All specific primers for amplification of specific genes, as well as the housekeeper gene $\beta$-actin, were designed and synthesized by Qiagen. All samples were run in triplicate.

Pulse-chase and cycloheximide (CHX) assays. The degradation rate of mRNA was assessed using a standard actinomycin D analysis. Following the addition of $5 \mu \mathrm{g} / \mathrm{ml}$ actinomycin D, Hep3B cells were treated with or without matrine. Subsequently, at different time points, the cells were harvested for isolation of the total RNA. The mRNA expression of MDM2 was detected by RT-qPCR.

Protein translation level was evaluated using a standard protein-synthesis inhibitor $\mathrm{CHX}$ assay. Briefly, the cells were pretreated with $100 \mu \mathrm{g} / \mathrm{ml} \mathrm{CHX}$ for $15 \mathrm{~min}$ at $4^{\circ} \mathrm{C}$ to arrest polyribosome migration. The cells were subsequently treated with or without matrine, and the cells were harvested and lyzed 
A

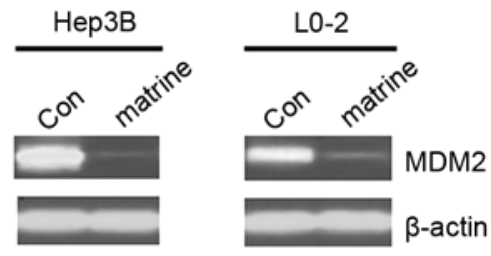

C
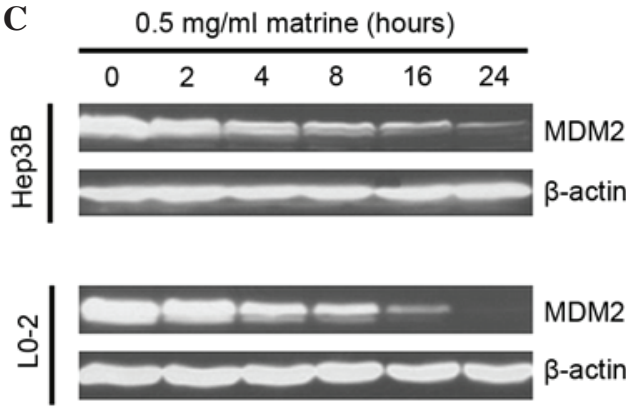

B Matrine $(\mathrm{mg} / \mathrm{ml})$
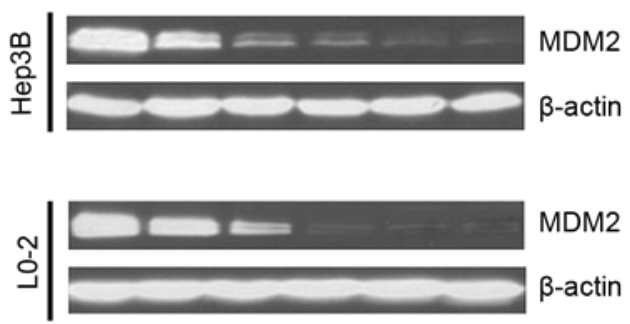

D

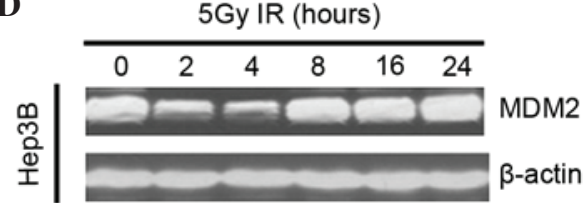

Figure 1. Matrine inhibits the expression of MDM2 in Hep3B and L0-2 cells. Western blotting was performed to determine (A) the protein expression levels of MDM2 following treatment with $4.0 \mathrm{mg} / \mathrm{ml}$ matrine for $24 \mathrm{~h}$,(B) the dose-response of MDM2 inhibition following treatment with the indicated concentrations of matrine for $24 \mathrm{~h},(\mathrm{C})$ the time-response of MDM2 inhibition following treatment with $0.5 \mathrm{mg} / \mathrm{ml}$ matrine for the indicated durations and (D) the protein expression of MDM2 following treatment with 5 Gy IR for the indicated durations. Western blotting was performed for both in Hep3B and L0-2 cells, and $\beta$-actin was used as a loading control. Con, control; MDM, mouse double-minute; IR, irradiation.

in a buffer containing $20 \mathrm{mM}$ Tris- $\mathrm{HCl}(\mathrm{pH} 8.0), 100 \mathrm{mM}$ $\mathrm{NaCl}, 5 \mathrm{mM} \mathrm{MgCl} 2,0.5 \%$ Triton X-100 and $500 \mathrm{U} / \mathrm{ml} \mathrm{RNAsin}$, as well as a cocktail of protease inhibitors. Fractionation was performed on a $15-45 \%(\mathrm{w} / \mathrm{v})$ sucrose gradient, centrifuged at $24,000 \times \mathrm{g}$ for $1 \mathrm{~h}$ at $4^{\circ} \mathrm{C}$. The fractions were collected from each gradient tube by upward replacement and absorption monitored at an optical density of $254 \mathrm{~nm}$, using a fractionator (Brandel, Gaithersburg, MD, USA). Lastly, immunoblotting was performed to observe concurrent turnover of MDM2.

MDM2 plasmid transfection. For transfection, Hep3B cells were seeded into 6-well plates at density of $2 \times 10^{5}$ cells/well. Following culturing to $70-80 \%$ confluence, the cells were harvested to make a cell suspension using cell medium. Both Lipofectamine 2000 transfection reagent (Invitrogen; Thermo Fisher Scientific, Inc.) and MDM2 overexpression plasmid were diluted with the Opti-MEM I medium (Thermo Fisher Scientific, Inc.) at a final concentration of $5 \%$ and $50 \mathrm{nM}$, respectively. The two mixtures were mixed and incubated at room temperature for an additional $20 \mathrm{~min}$. Following incubation, the above transfection mixture was added to new 6-well plates. The Hep3B cell suspensions (final concentration for MDM2 plasmid, $5 \mathrm{nM}$ ) were overlaid onto the transfection mixture. Following incubation at $37^{\circ} \mathrm{C}$ for $4 \mathrm{~h}$, the media was removed and the cells were cultured with fresh cell medium.

\section{3-(4,5-dimethyl-2-thiazolyl)-2,5-diphenyl-2-H-tetrazolium} bromide (MTT) assay. Hep3B and MDM2-overexpressing Hep3B cells were seeded at a density of $3 \times 10^{3}$ cells/well in 96-well plates for $24 \mathrm{~h}$. Different concentrations of matrine were added to the cells for times indicated. Following treatment, the supernatant in each well was replaced with $90 \mu 1$ DMEM (without FBS) and $10 \mu \mathrm{l}$ MTT solution (final concentration, $5 \mathrm{mg} / \mathrm{ml}$ ), and incubated at $37^{\circ} \mathrm{C}$ for an additional $4 \mathrm{~h}$. The liquid in each well was carefully aspirated and $150 \mu \mathrm{l}$ dimethylsulfoxide was added to dissolve the formazan product. The optical density was quantified using Multi-Detection Microplate Readers (Synergy 2; Bio-Tek Instruments, Inc., Winooski, VT, USA) at a wavelength of $570 \mathrm{~nm}$. The control and treated group data are expressed as mean \pm standard deviation of three independent experiments.

Flow cytometry. The matrine-induced cell cycle arrest and cell death were assessed by flow cytometry. For the cell-cycle sample preparation, the harvested cells were washed twice with phosphate-buffered saline (PBS) and fixed overnight with $70 \%$ ethanol at $4^{\circ} \mathrm{C}$. After washing three times with PBS, the cells were resuspended with $0.5 \mathrm{ml}$ PBS containing $20 \mu \mathrm{g} / \mathrm{ml} \mathrm{PI}$ and $1 \mu \mathrm{g} / \mathrm{ml}$ RNase A. Following incubation at $4^{\circ} \mathrm{C}$ for an additional $30 \mathrm{~min}$, the cells were analyzed using a FACScan (Becton-Dickinson, San Jose, CA, USA) with WinList software (Verity Software House, Topsham, ME, USA). For analysis of cell death type, the matrine-treated cells were harvest and washed twice with PBS. The cells were subsequently suspended in $400 \mu \mathrm{l}$ binding buffer containing $10 \mu \mathrm{l} \mathrm{PI}$ and $5 \mu \mathrm{l}$ Annexin V-FITC, and were incubated for $20 \mathrm{~min}$ at room temperature in the dark, followed by flow cytometric analysis.

Statistic analysis. The differences between the groups were examined for statistical significance using the one-way analysis of variance followed by Dunnett's post-hoc test using SPSS 

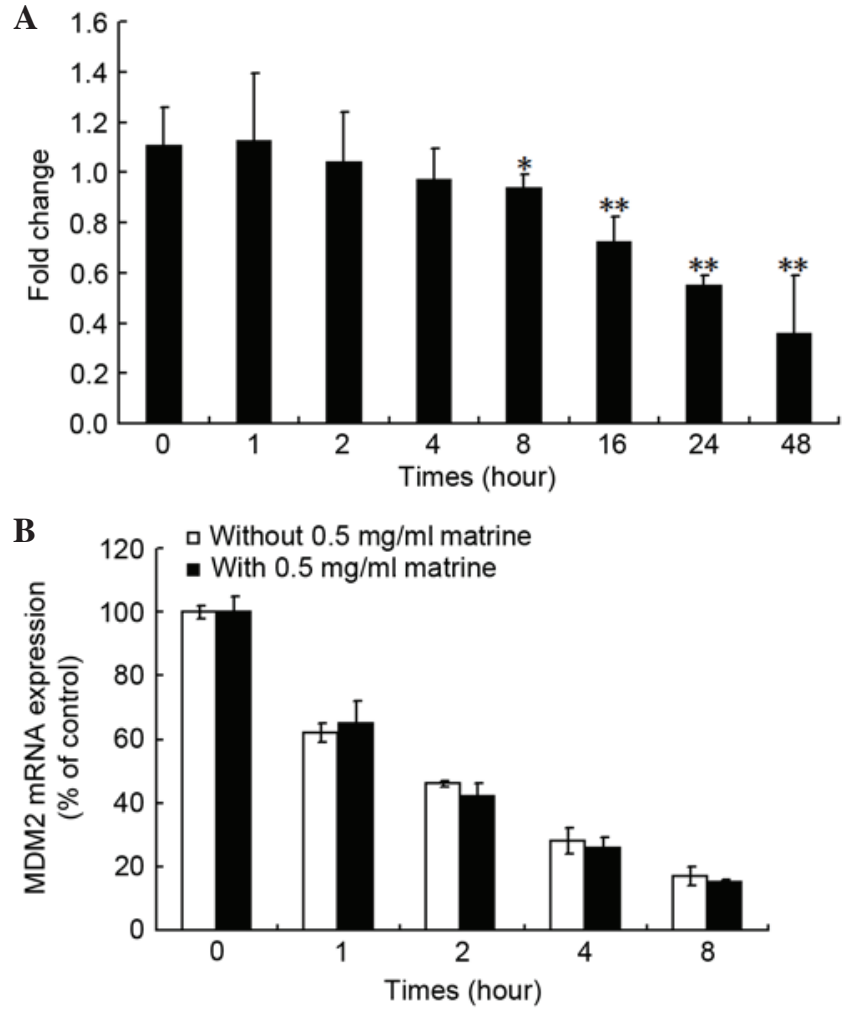

C

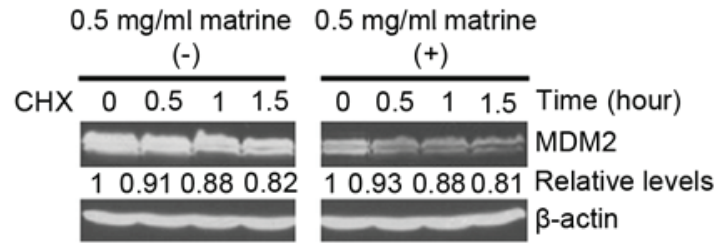

Figure 2. Examination of the molecular mechanism by which matrine reduces MDM2. (A) The mRNA expression of MDM2 in Hep3B cells was determined by RT-qPCR following treatment with $0.5 \mathrm{mg} / \mathrm{ml}$ matrine for the indicated durations. The data is shown as the fold change. (B) Hep3B cells were pre-treated with or without $10 \mu \mathrm{M} \mathrm{CHX}$ for $10 \mathrm{~min}$, followed by incubation with or without $0.5 \mathrm{mg} / \mathrm{ml}$ matrine for $4 \mathrm{~h}$, then $5 \mathrm{mg} / \mathrm{ml}$ actinomycin D was added. Cells were then harvested and the mRNA expression levels of MDM2 were determined by RT-qPCR. The data are presented as the mean \pm standard deviation $\left({ }^{*} \mathrm{P}<0.05\right.$ and ${ }^{* *} \mathrm{P}<0.01$ compared with the untreated $0 \mathrm{~h}$ samples). (C) A CHX pulse-chase assay was performed to detect MDM2 turnover in Hep3B cells treated with or without $0.5 \mathrm{mg} / \mathrm{ml}$ matrine for $4 \mathrm{~h}$. The numerical labels under each protein band represents the expression levels after normalization against $\beta$-actin, compared with untreated samples (defined as 1 unit). MDM, mouse double-minute; $\mathrm{CHX}$, cycloheximide; RT-qPCR, reverse transcription-quantitative polymerase chain reaction.

version 19.0 software (SPSS, Inc., Chicago, IL, USA). P<0.05 was considered to indicate a statistically significant difference.

\section{Results}

MDM2 expression in matrine-treated Hep3B and LO-2 cells. To assess whether MDM2 expression levels were influenced by matrine, western blotting analysis was performed. It was revealed that matrine notably downregulated MDM2 in the two studied cell lines (Fig. 1A). Matrine suppressed the protein expression of MDM2 in a dose-dependent manner, even at low concentrations (Fig. 1B). The matrine-induced
MDM2 inhibition occurred at $\sim 4$ h post-treatment and was followed by a steady-state downregulation (Fig. 1C), with a style distinct from irradiation-treament that instead induced a rapid and transient (1-2 h) decrease of MDM2 expression, followed by a clear upregulation (Fig. 1D).

Matrine-induced decrease of the mRNA synthesis of MDM2. The present study next investigated the mechanism by which matrine suppress the expression of MDM2. As shown in Fig. 2A, the mRNA expression of MDM2 was clearly inhibited by matrine. To investigate whether the matrine-induced MDM2 mRNA decrease is associated with mRNA stability, pulse-chase and RT-qPCR reactions were performed. As shown in Fig. 2B, matrine caused no affect on the mRNA stability of MDM2. MDM2 protein stabilization was further assessed using a standard CHX pulse-chase assay. As shown in Fig. 2C, compared with the control groups, the half-life of MDM2 was not affected by matrine, suggesting that matrine decreases MDM2 via the inhibition of mRNA synthesis. Enhanced expression of $\mathrm{p} 73$ by matrine is a result of matrine-mediated inhibition of MDM2, since MDM2 can compete with p73 for binding to its upstream effectors (17).

The present study investigated whether the matrine-induced MDM2 decrease can affect the expression of p73 $\alpha$. Firstly, a possible direct influence of matrine on p73 mRNA level was investigated by comparing it with the known effect of benzo(a) pyrene on the mRNA expression of p73 (26). As shown in Fig. 3A, benzo(a)pyrene increased p73 transcription in the cells. By contrast, matrine failed to either increase or decrease the mRNA expression of p73. Whether matrine can affect p73 translation was next determined. As shown in Fig. 3B, no difference in the expression of p73 was detected in the presence or absence of the protein synthesis, as assessed by $\mathrm{CHX}$ treatment. Lastly, the turnover of $\mathrm{p} 73$ protein was measured in matrine-treated cells, as shown in Fig. 3C. Compared with the control groups, matrine notably increased the half-life of p73. These results suggested that the observed matrine-upregulated expression of p73 in Hep3B cells occurs only at the post-translational level. Additionally, the expression of p73 after matrine treatment in Hep3B cells was assessed, as shown in Fig. 3D. Matrine increased the expression of p73 following the downregulation of MDM2.

p73 cell-cycle arrest function is not activated in matrine-treated Hep3B cells. p21 and PUMA are two downstream targets of p73. Therefore, the present study examined the expression levels of p21 and PUMA in matrine-treated Hep3B cells. As shown in Fig. 4A, benzo(a)pyrene clearly increased the expression levels of p21 and PUMA, as well as the mRNA expression of MDM2. By contrast, matrine failed to increase or decrease the expression levels of the above genes. Additionally, as shown in Fig. 4B, the matrine-induced p73 protein increase was not to the same level as that of epotoside-induced. The data in Fig. 4B also demonstrated that epotoside increased the protein expression levels of p21 and PUMA, whereas matrine decreased the expression levels. In addition, matrine failed to induce accumulation of the p73 activated form (p73 $\alpha$-Try99), compared with epotoside, which increased p $73 \alpha$-Try99 levels. The cell-cycle analysis also confirmed that p21 was not functional in the 

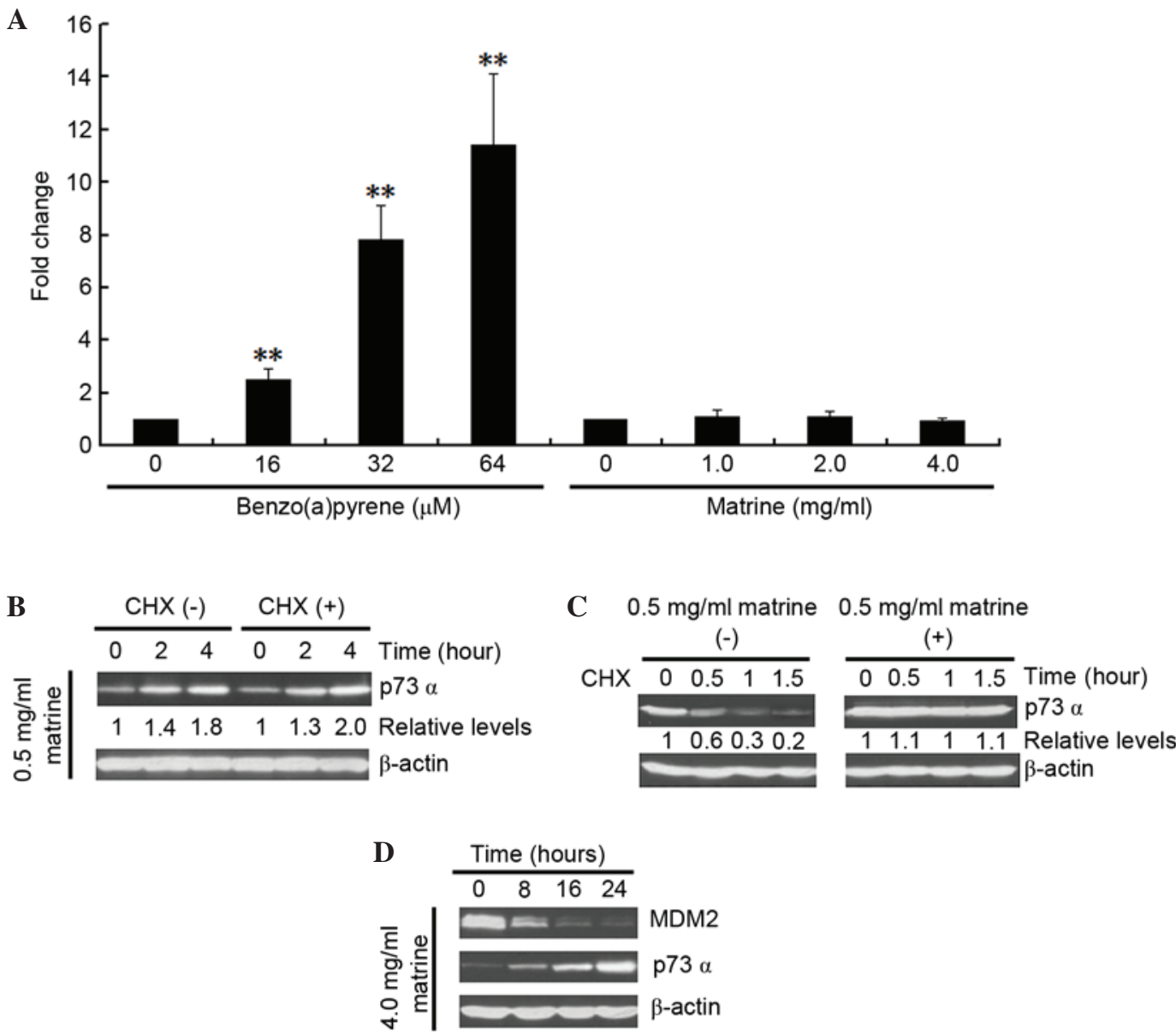

Figure 3. Matrine-induced downregulation of MDM2 results in an increase in the expression of p73 $\alpha$. (A) Hep3B cells were treated with different concentrations of either benzo(a)pyrene $(16,32$ or $64 \mu \mathrm{M})$ or matrine $(1.0,2.0$ or $4.0 \mathrm{mg} / \mathrm{ml})$ for $12 \mathrm{~h}$. The mRNA expression levels of p53 were assessed by reverse transcription-quantitative polymerase chain reaction. The data are presented as the mean \pm standard deviation $\left({ }^{* *} \mathrm{P}<0.01\right.$ compared with the untreated $0 \mathrm{~h}$ group) samples. (B) Hep3B cells were pre-treated with or without $10 \mu \mathrm{M} \mathrm{CHX}$ for $10 \mathrm{~min}$, followed by an incubation with $0.5 \mathrm{mg} / \mathrm{ml} \mathrm{matrine}$. The cell extracts from 0 or 2 or $4 \mathrm{~h}$ treatment groups were assessed by western blotting to determine the expression of p73 $\alpha$. (C) A pulse-chase assay for p73a turnover was performed in Hep3B cells treated with $0.5 \mathrm{mg} / \mathrm{ml}$ matrine. (D) Hep3B cells treated with $4.0 \mathrm{mg} / \mathrm{ml}$ matrine for the indicated durations were assessed for the expression levels of MDM2 and p73 $\alpha$ by western blotting. $\beta$-actin was used as a loading control. CHX, cycloheximide; MDM, mouse double-minute.

matrine-treated cells. As shown in Fig. 4C, matrine failed to induce G1 arrest. By contrast, epotoside clearly induced cell accumulation in G1 phase, whereas matrine decreased cell numbers in $\mathrm{G} 1, \mathrm{~S}$ and $\mathrm{G} 2 / \mathrm{M}$.

Matrine inhibited the expression of IAP3 in MDM2-overexpressing Hep3B cells. IAP3 is a translational target of MDM2, which exhibits reduced expression level following MDM2 silencing (21). The present study assessed the expression levels of IAP3. As shown in Fig. 5A, matrine markedly decreased the expression levels of MDM2 and IAP3, whereas both genes were increased in the epotoside-treated cells. To investigate whether MDM2 inhibition affected the expression of IAP3 in matrine-treated Hep3B cells, an MDM2-overexpressing Hep3B cells cell line was treated with matrine. As shown in Fig. 5B, a more marked decrease of IAP 3 was induced in the matrine-treated MDM2-overexpressing Hep3B cells compared with in the matrine-treated negative plasmid-transfected Hep3B cells. Additionally, the IAP3 protein stability was also evaluated in the matrine-treated Hep3B cells. As shown in Fig. 5C, compared with the control group, matrine caused no effect on IAP3 protein stability. These results suggested that matrine can strongly suppress the expression of IAP3 in MDM2-overexpressing Hep3B cells at both the mRNA and protein expression levels.

Matrine sensitized Hep3B cells to epotoside-induced apoptosis. The present study assessed the effect of matrine on Hep3B and MDM2-overexpressing Hep3B cell viabilities using an MTT assay. As shown in Fig. 6A, matrine exhibited cytotoxic activity in each of the cell lines. Matrine exhibited a more marked cytotoxic effect on MDM2-overexpressing Hep3B cells that express very high level of MDM2. To investigate the mechanism by which matrine induces MDM2-overexpressing Hep3B cell death, the activation of several apoptotic effectors was assessed. As shown in Fig. 6B, cleavage of caspases-3 and -9, and PARP in MDM2-overexpressing Hep3B cells was observed $4 \mathrm{~h}$ post-treatment. Whether matrine has synergistic effects on epotoside-induced apoptosis was determined by treating the Hep3B cells with both. When administered alone, a 24-h treatment induced 27.4 and $34.2 \%$ apoptosis for etoposide and matrine treatment, respectively. When the same doses were administered to cells in combination, as shown in Fig. 6C, 
A
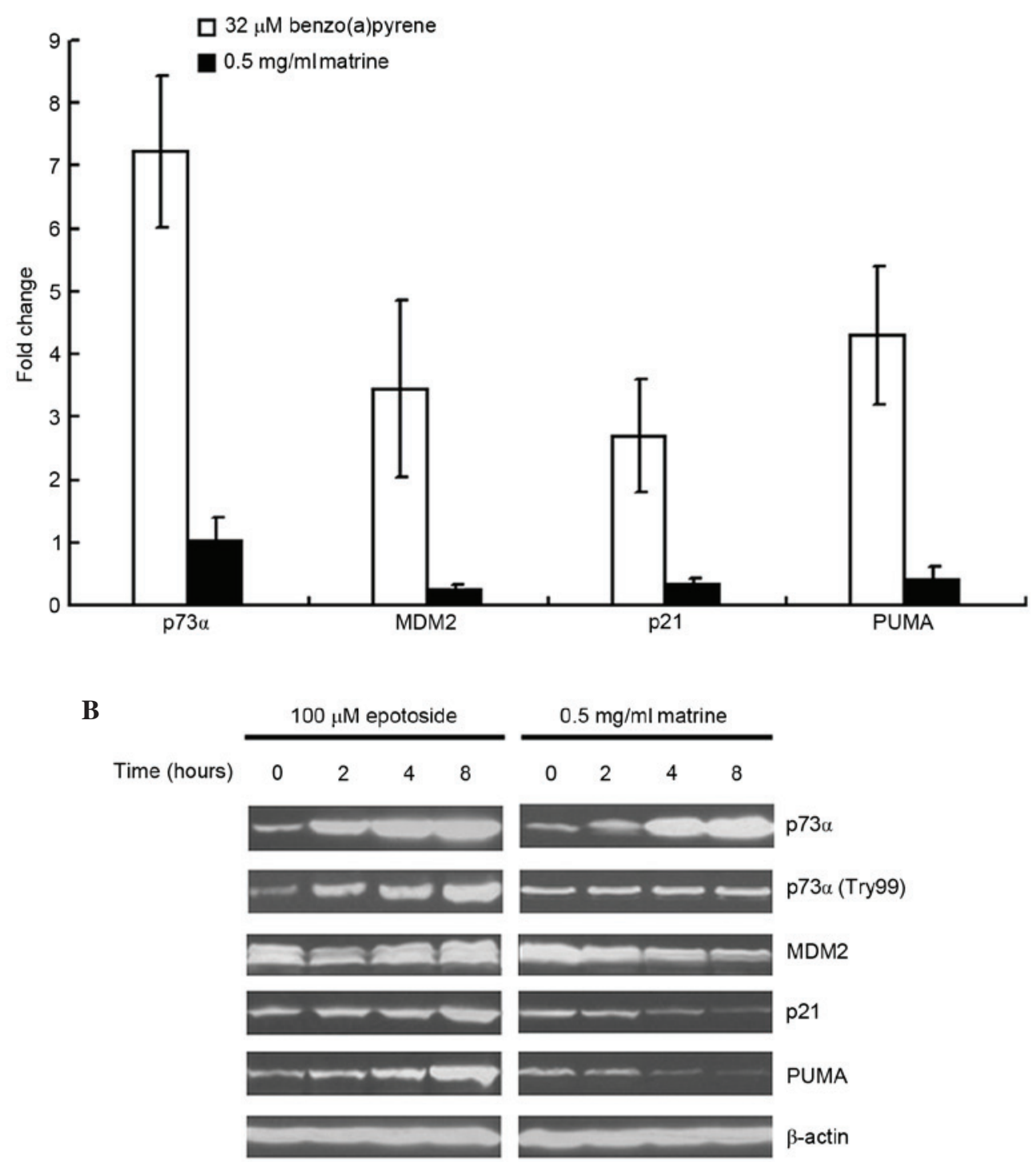

C

Untreated

$100 \mu \mathrm{M}$ epotoside

$0.5 \mathrm{mg} / \mathrm{ml}$ matrine
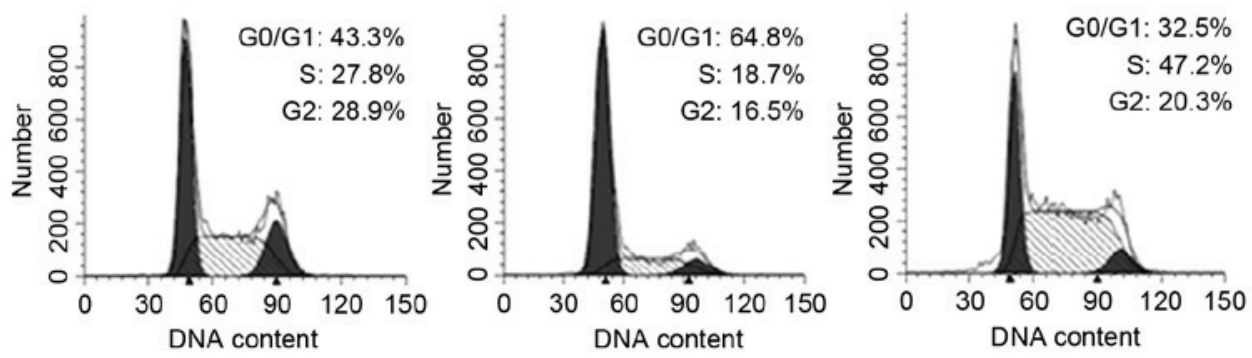

Figure 4. Matrine-increased expression of p73 $\alpha$ causes no induction of its targets, p21 and PUMA, as compared with treatment with Benzo(a)pyrene or epotoside. (A) Hep3B cells were treated with $32 \mu \mathrm{M}$ Benzo(a)pyrene or $0.5 \mathrm{mg} / \mathrm{ml}$ matrine for $12 \mathrm{~h}$ and subsequently, the mRNA expression levels of p73 $\alpha$, MDM2, p21 and PUMA were assessed by reverse transcription-quantitative polymerase chain reaction. The data are presented as the fold change compared with the control group. (B) Hep3B cells were treated with either $100 \mu \mathrm{M}$ epotoside or $0.5 \mathrm{mg} / \mathrm{ml}$ matrine for various durations. The protein expression levels of p73 $\alpha$, MDM2, p21 and PUMA were assessed by western blotting. $\beta$-actin was used as a loading control. (C) Cell-cycle analysis in Hep3B cells was performed $4 \mathrm{~h}$ post-treatment with $100 \mu \mathrm{M}$ epotoside or $0.5 \mathrm{mg} / \mathrm{ml}$ matrine. MDM, mouse double-minute; PUMA, p53 upregulated modulator of apoptosis.

compared with the control and either alone treated groups, the apoptosis ratio was significantly increased in the combination group $(>70 \% ; \mathrm{P}<0.01)$. These results suggested that matrine sensitized Hep3B cells to epotoside-induced apoptosis.

\section{Discussion}

The p53 tumor suppressor gene serves a crucial roles in maintaining the integrity of the genome and the defense 

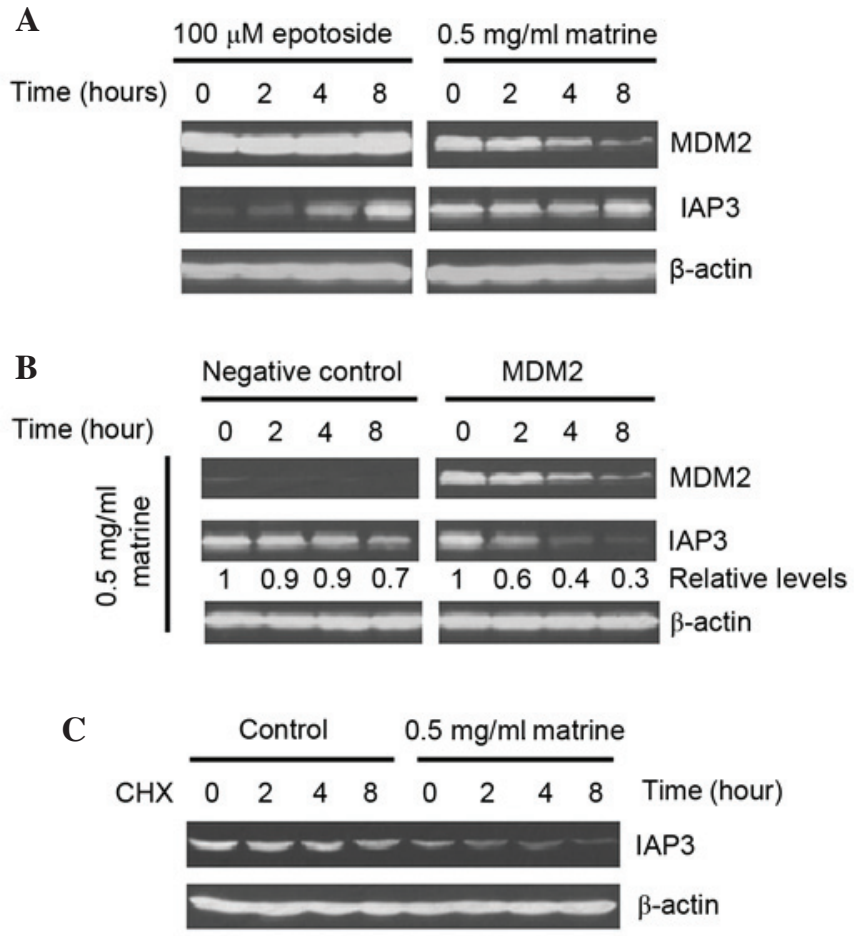

Figure 5. Effect of epotoside-increased and matrine-decreased MDM2 on the expression of IAP3. (A) Hep3B cells were incubated with either $100 \mu \mathrm{M}$ epotoside or $0.5 \mathrm{mg} / \mathrm{ml}$ matrine for the indicated duration. The protein expression levels of MDM2 and IAP3 were assessed by western blotting. (B) Normal and MDM2 overexpression Hep3B cells were treated with $0.5 \mathrm{mg} / \mathrm{ml}$ matrine for the indicated durations. The transfection efficiency of MDM2 and IAP3 in MDM2-overexpressing Hep3B cells were evaluated by western blotting (C) The protein stability of IAP3 was detected using a pulse-chase assay following treatment with $0.5 \mathrm{mg} / \mathrm{ml}$ matrine. $\beta$-actin was used as a loading control. MDM, mouse double-minute; IAP, inhibitor of apoptosis protein CHX, cycloheximide.

against tumor metastasis and is mutated or deleted in $\sim 50 \%$ of human cancer types (12). However, numerous tumors retain wild-type p53, suggesting that the above tumor cells contain abnormalities of other genes, including overexpression of the p53 negative regulator, MDM2. MDM2 overexpression has been reported in $\sim 1 / 3$ human cancer cells that contain wild-type p53 gene (27). Therefore, MDM 2 can be considered as a proto-oncogene. The present study used a p53-deficient cell model, Hep3B cells, to investigate the anticancer activity of a known Chinese herbal medicine, matrine. It was found that matrine notably decreased the mRNA expression of MDM2, which resulted in an increase of $\mathrm{p} 73$. However, the primary function of p73 was not activated, which was reflected by the failure to induce p21 and PUMA. Notably, the matrine-induced downregulation also resulted in decreased expression of the apoptotic inhibitor, IAP3.

IAPs form a family of caspase inhibitors that inhibit the downstream portion of the apoptosis pathway and inhibit cell death in response to multiple stimuli (28). There are currently eight known human IAP family members, with IAP3 being the best characterized member (29). The antiapoptotic roles of IAP3 have been attributed to its ability to directly bind to and inhibit the activated forms of caspase-3, -7 and -9 , which are important executors of the intrinsic apoptosis pathway (30). Additionally, overexpression of IAP3 has been observed in a variety of human cancer types $(31,32)$. In the present study, it was revealed that IAP3 was notably inhibited by matrine at both the transcriptional and translational levels. Since the mRNA expression of IAP3 can be regulated by MDM2 (33), the present study further examined whether matrine-induced IAP3 inhibition was associated with a decrease in MDM2 using an MDM2-overexpression Hep3B cell model. It was revealed that more inhibition of IAP3 was observed in the MDM2-overexpressing Hep3B cells compared with in the wild-type Hep3B cells. Consistent with previous studies which reported that knockdown of endogenous MDM2 with siRNA resulted in decreased IAP3 activity (22). The present study also demonstrated that downregulation of MDM2 in the MDM2-overexpressing Hep3B cells resulted in potent cell apoptosis.

The Hep3B cell apoptosis was predominantly attributed to matrine-induced IAP3 inhibition, which was further confirmed by the finding of no induction of p73 function in the cells. In the present study, although the matrine-induced MDM2 inhibition resulted in an increased expression of p73, the expression of p21, a p27 downstream target, was inhibited rather than activated in the matrine-treated Hep3B cells. Another important p73 transcriptional target for execution of mitochondria-dependent apoptosis, PUMA, was also not increased and rather decreased in the matrine-treated Hep3B cells. Although the present study did not investigate the reason why biological functions of p21 and PUMA were not activated by the matrine-increased p73, it was hypothesized that, similar to MDM2, the mRNA synthesis of p21 and PUMA may be inhibited by matrine, even though the increased p73 can bind to its promoters. However, the molecular mechanism underlying the above remains to be elucidated. The most important observations of the present study were that matrine notably increased the sensitivity of the p53-deficient Hep3B cells to epotoside-induced apoptosis. It is well known that epotoside and numerous other anticancer alkylating drugs kill cancer cells through induction of DNA damage, the latter in turn increases immediate accumulation and activation of p53 family members through ATM-Chk2 and ATR-Chk1 pathways, which are activated by DNA double-strand breaks and single-stranded DNA, respectively $(11,34)$. The activated p73, similar to p53, can bind to the promoters of p21 and PUMA, which in turn execute cell cycle arrest and mintochondria-dependent cell apoptosis (35). The activated p73 also triggers mRNA expression of its negative effector, MDM2. This p73-induced increase of MDM2 expression begins to compete with p73 for binding to the p300/CBP N-terminus and suppresses its biological functions (17). In addition to interacting with and inactivating $\mathrm{p} 53$, there is evidence to suggest that MDM2 can also interact with other molecules, including specific protein and RNA, which may serve a p53-independent role in oncogenesis (e.g. induction of IAP3) (33). Aside from regulating its downstream effectors, MDM2 itself can be modulated by various upstream signals. For example, cell growth factor-induced activation of phosphatidylinositol 3-kinase-Akt can phosphorylate MDM2-serine 166 and 186 in the cytoplasm, which in turn triggers translocation of MDM2 from the cytoplasm into the nucleus (36). For anther case, cellular stress and DNA damage can induce dephosphorylation of the central 


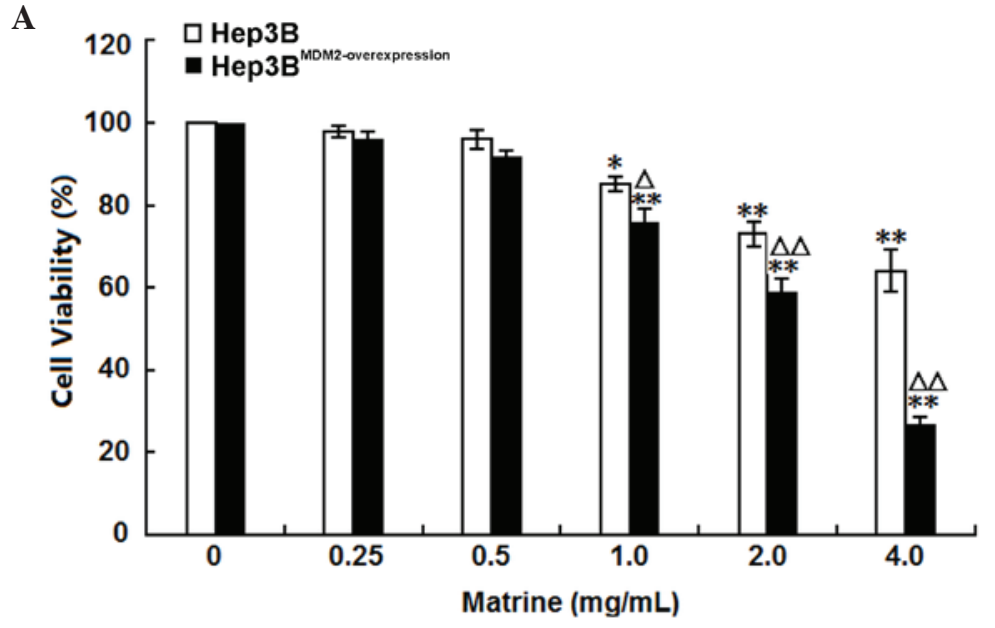

B
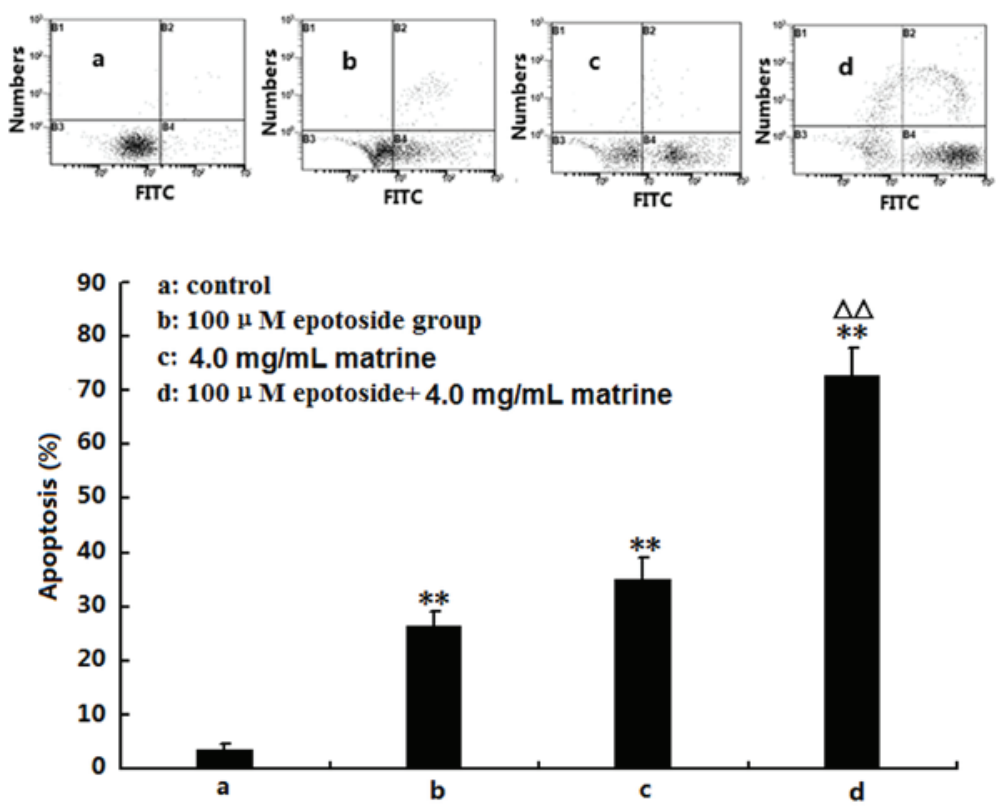

C

$100 \mu \mathrm{M}$ Epotoside $\quad 4.0 \mathrm{mg} / \mathrm{mL}$ matrine

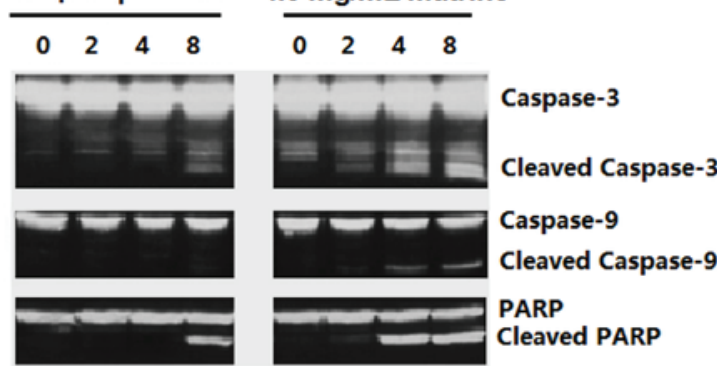

Figure 6. Apoptotic effect of matrine on Hep3B and MDM2-overexpressing Hep3B cells. (A) Hep3B and MDM2-overexpressing Hep3B cells were treated with $0.25-4.0 \mathrm{mg} / \mathrm{ml}$ matrine for $24 \mathrm{~h}$. The cell viability was assessed using a 3-(4,5-dimethyl-2-thiazolyl)-2,5-diphenyl-2-H-tetrazolium bromide assay. The data are presented as the mean \pm standard deviation $\left(\mathrm{n}=3\right.$; ${ }^{*} \mathrm{P}<0.05$ and ${ }^{* *} \mathrm{P}<0.01$ compared with the corresponding control group; ${ }^{\Delta} \mathrm{P}<0.05$ and ${ }^{\Delta \Delta} \mathrm{P}<0.01$ compared with the untransfected Hep3B cells). (B) Hep3B cells were treated with $100 \mu \mathrm{M}$ epotoside or $4.0 \mathrm{mg} / \mathrm{ml}$ matrine, alone or in combination, for $24 \mathrm{~h}$. Cell apoptosis was analyzed by dual-parameter flow cytometry utilizing annexin V-FITC and propidium iodide, and the results of three independent experiments were pooled and average values are presented. Group a, control; group b, $100 \mu \mathrm{M}$ epotoside; group c, $4.0 \mathrm{mg} / \mathrm{ml} \mathrm{matrine;} \mathrm{group} \mathrm{d,} 100 \mu \mathrm{M} \mathrm{epotoside}+4.0 \mathrm{mg} / \mathrm{ml}$ matrine. The data are presented as the mean \pm standard deviation $\left(\mathrm{n}=3 ;{ }^{* *} \mathrm{P}<0.01\right.$ compared with the control group; ${ }^{\Delta \Lambda} \mathrm{P}<0.01$ compared with the epotoside group). (C) Hep3B cells were treated with $100 \mu \mathrm{M}$ epotoside or $4.0 \mathrm{mg} / \mathrm{ml}$ matrine. The protein expression levels of cleaved and total Caspase-3, -9 and PARP were assessed by western blotting. FITC, fluorescein isothiocyanate; PARP, poly ADP ribose polymerase. 
acidic domain of MDM2, which may result in inhibition of the nuclear translocation for MDM2, or accumulation in the cytoplasm (37). The present results suggested a functional role for MDM2 in tumor development, which extends thef current understanding of resistance to chemical-therapy in cancer.

In conclusion, the present study indicated that matrine causes cytotoxicity and induces apoptosis in p53-deficient Hep3B cells. The major underlying mechanism is the inhibition of the MDM2-IAP3 pathway. Therefore, it is hypothesized that matrine may be an interesting candidate drug in the development of therapies against p53-defective cancer cells.

\section{References}

1. Hu ZL, Zhang JP, Qian DH, Lin W, Xie WF, Zhang XR and Chen WZ: Effects of matrine on mouse splenocyte proliferation and release of interleukin-1 and -6 from peritoneal macrophages in vitro. Zhongguo Yao Li Xue Bao 17: 259-261, 1996.

2. Cheng H, Xia B, Zhang L, Zhou F, Zhang YX, Ye M, Hu ZG, Li J, Li J, Wang ZL, et al: Matrine improves 2,4,6-trinitrobenzene sulfonic acid-induced colitis in mice. Pharmacol Res 53: 202-208, 2006

3. Liu J, Zhu M, Shi R and Yang M: Radix Sophorae flavescentis for chronic hepatitis B: A systematic review of randomized trials. Am J Chin Med 31: 337-354, 2003.

4. Tan C, Qian X, Jia R, Wu M and Liang Z: Matrine induction of reactive oxygen species activates p38 leading to caspase-dependent cell apoptosis in non-small cell lung cancer cells. Oncol Rep 30: 2529-2535, 2013.

5. Liu XS, Jiang J, Jiao XY, Wu YE and Lin JH: Matrine-induced apoptosis in leukemia U937 cells: Involvement of caspases activation and MAPK-independent pathways. Planta Med 72: 501-506, 2006

6. Jiang H, Hou C, Zhang S, Xie H, Zhou W, Jin Q, Cheng X, Qian $\mathrm{R}$ and Zhang X: Matrine upregulates the cell cycle protein E2F-1 and triggers apoptosis via the mitochondrial pathway in K562 cells. Eur J Pharmacol 559: 98-108, 2007.

7. Hu MJ, Zeng H, Wu YL, Zhang YP, Zhang S, Qiao MM and $\mathrm{Fu} \mathrm{H}$ : Synergistic effects of matrine and 5-fluorouracil on tumor growth of the implanted gastric cancer in nude mice. Chin J Dig Dis 6: 68-71, 2005.

8. Zhang JQ, Li YM, Liu T, He WT, Chen YT, Chen XH, Li X, Zhou WC, Yi JF and Ren ZJ: Antitumor effect of matrine in human hepatoma G2 cells by inducing apoptosis and autophagy. World J Gastroenterol 16: 4281-4290, 2010.

9. Tanigawa S, Fujii M and Hou DX: Stabilization of p53 is involved in quercetin-induced cell cycle arrest and apoptosis in HepG2 cells. Biosci Biotechnol Biochem 72: 797-804, 2008.

10. Schavolt KL and Pietenpol JA: p53 and Delta Np63 alpha differentially bind and regulate target genes involved in cell cycle arrest, DNA repair and apoptosis. Oncogene 26: 6125-6132, 2007.

11. Reinhardt HC, Aslanian AS, Lees JA and Yaffe MB: p53-deficient cells rely on ATM- and ATR-mediated checkpoint signaling through the p38MAPK/MK2 pathway for survival after DNA damage. Cancer Cell 11: 175-189, 2007.

12. Michael D and Oren M: The p53 and Mdm2 families in cancer. Curr Opin Genet Dev 12: 53-59, 2002.

13. Chène P: Inhibiting the p53-MDM2 interaction: An important target for cancer therapy. Nat Rev Cancer 3: 102-109, 2003.

14. Shiraishi T and Nielsen PE: Down-regulation of MDM2 and activation of p53 in human cancer cells by antisense 9 -aminoacridine-PNA (peptide nucleic acid) conjugates. Nucleic Acids Res 32: 4893-4902, 2004.

15. Ongkeko WM, Wang XQ, Siu WY, Lau AW, Yamashita K, Harris AL, Cox LS and Poon RY: MDM2 and MDMX bind and stabilize the p53-related protein p73. Curr Biol 9: 829-832, 1999.

16. Dobbelstein M, Wienzek S, König C and Roth J: Inactivation of the p53-homologue p73 by the mdm2-oncoprotein. Oncogene 18: 2101-2106, 1999 .
17. Zeng X, Chen L, Jost CA, Maya R, Keller D, Wang X, Kaelin WG Jr, Oren M, Chen J and Lu H: MDM2 suppresses p73 function without promoting p73 degradation. Mol Cell Biol 19: 3257-3266, 1999.

18. Kowalik TF, DeGregori J, Leone G, Jakoi L and Nevins JR: E2F1-specific induction of apoptosis and p53 accumulation, which is blocked by Mdm2. Cell Growth Differ 9: 113-118, 1998.

19. Froment P, Dupont J and Christophe-Marine J: Mdm2 exerts pro-apoptotic activities by antagonizing insulin-like growth factor-I-mediated survival. Cell Cycle 7: 3098-3103, 2008

20. Pereboom TC, van Weele LJ, Bondt A and MacInnes AW: A zebrafish model of dyskeratosis congenita reveals hematopoietic stem cell formation failure resulting from ribosomal protein-mediated p53 stabilization. Blood 118: 5458-5465, 2011.

21. Huang $X, \mathrm{Wu} Z$, Mei $Y$ and Wu M: XIAP inhibits autophagy via XIAP-Mdm2-p53 signalling. Embo J 32: 2204-2216, 2013.

22. Zheng M, Yang J, Xu X, Sebolt JT, Wang S and Sun Y: Efficacy of MDM2 inhibitor MI-219 against lung cancer cells alone or in combination with MDM2 knockdown, a XIAP inhibitor or etoposide. Anticancer Res 30: 3321-3331, 2010.

23. Deb SP, Singh S and Deb S: MDM2 overexpression, activation of signaling networks, and cell proliferation. Subcell Biochem 85: 215-234, 2014

24. Jones SN, Hancock AR, Vogel H, Donehower LA and Bradley A: Overexpression of Mdm2 in mice reveals a p53-independent role for Mdm2 in tumorigenesis. Proc Natl Acad Sci USA 95: 15608-15612, 1998.

25. Jiang Y, Zhang XY, Sun L, Zhang GL, Duerksen-Hughes P, Zhu XQ and Yang J: Methyl methanesulfonate induces apoptosis in p53-deficient H1299 and Hep3B cells through a caspase 2and mitochondria-associated pathway. Environ Toxicol Pharmacol 34: 694-704, 2012.

26. Jiang Y, Rao K, Yang G, Chen X, Wang Q, Liu A, Zheng H and Yuan J: Benzo(a)pyrene induces p73 mRNA expression and necrosis in human lung adenocarcinoma H1299 cells. Environ Toxicol 27: 202-210, 2012

27. Yu Q, Li Y, Mu K, Li Z, Meng Q, Wu X, Wang Y and Li L: Amplification of Mdmx and overexpression of MDM2 contribute to mammary carcinogenesis by substituting for p53 mutations. Diagn Pathol 9: 71, 2014.

28. Chow KU, Nowak D, Boehrer S, Ruthardt M, Knau A, Hoelzer D, Mitrou PS and Weidmann E: Synergistic effects of chemotherapeutic drugs in lymphoma cells are associated with down-regulation of inhibitor of apoptosis proteins (IAPs), prostate-apoptosis-response-gene 4 (Par-4), death-associated protein (Daxx) and with enforced caspase activation. Biochem Pharmacol 66: 711-724, 2003.

29. Lederman M, Meir T, Zeschnigk M, Pe'er J and Chowers I: Inhibitor of apoptosis proteins gene expression and its correlation with prognostic factors in primary and metastatic uveal melanoma. Curr Eye Res 33: 876-884, 2008.

30. Eckelman BP, Salvesen GS and Scott FL: Human inhibitor of apoptosis proteins: Why XIAP is the black sheep of the family. EMBO Rep 7: 988-994, 2006.

31. Wang R, Li B, Wang X, Lin F, Gao P, Cheng SY and Zhang HZ: Inhibiting XIAP expression by RNAi to inhibit proliferation and enhance radiosensitivity in laryngeal cancer cell line. Auris Nasus Larynx 36: 332-339, 2009.

32. Qiao L, Li GH, Dai Y, Wang J, Li Z, Zou B, Gu Q, Ma J, Pang R, Lan HY and Wong BC: Gene expression profile in colon cancer cells with respect to XIAP expression status. Int J Colorectal Dis 24: 245-260, 2009.

33. Gu L, Zhu N,Zhang H,Durden DL,Feng Y and Zhou M: Regulation of XIAP translation and induction by MDM2 following irradiation. Cancer Cell 15: 363-375, 2009.

34. Nur-E-Kamal A, Li TK, Zhang A, Qi H, Hars ES and Liu LF: Single-stranded DNA induces ataxia telangiectasia mutant (ATM)/p53-dependent DNA damage and apoptotic signals. J Biol Chem 278: 12475-12481, 2003.

35. Sasaki Y, Morimoto I, Ishida S, Yamashita T, Imai K and Tokino T: Adenovirus-mediated transfer of the p53 family genes, p73 and p51/p63 induces cell cycle arrest and apoptosis in colorectal cancer cell lines: Potential application to gene therapy of colorectal cancer. Gene Ther 8: 1401-1408, 2001.

36. Blattner C, Hay T, Meek DW and Lane DP: Hypophosphorylation of Mdm2 augments p53 stability. Mol Cell Biol 22: 6170-6182, 2002.

37. Okamoto K, Li H, Jensen MR, Zhang T, Taya Y, Thorgeirsson SS and Prives C: Cyclin G recruits PP2A to dephosphorylate Mdm2. Mol Cell 9: 761-771, 2002. 